\title{
PENGARUH MODEL PEMBELAJARAN ADVANCE ORGANIZER TERHADAP HASIL BELAJAR SISWA SMA NEGERI 3 SIGI PADA MATERI LARUTAN ELEKTROLIT DAN NON ELEKTROLIT
}

\author{
The Influence of Advance Organizer Learning Model Toward Learning Achievements of \\ Students at SMA Negeri 3 Sigi on the Topic Electrolyte and Non-Electrolyte Solutions
}

\author{
* Maryam, Ratman dan Purnama Ningsih \\ Pendidikan Kimia/FKIP - Universitas Tadulako, Palu - Indonesia 94118 \\ Received 1 March 2018, Revised 2 April 2018, Accepted 2 May 2018
}

\begin{abstract}
This study aimed to determine the influence of advance organizer learning model toward learning achievements of students at SMA Negeri 3 Sigi on the topic electrolyte and non-electrolyte solutions. This study was a quasi-experiment with pretest-posttest control group design using two groups of students, i.e 34 Class $X B$ as an experimental group, and 34 Class $X A$ as a control group. Data of learning achievements of students was analyzed using t-test two parties statistical analysis. Results showed that the average values of experiment class ( $\left.\mathrm{X}_{1}\right)$ was 77.15 with a standard deviation of 11.59 , while the average values of control class $\left(\mathrm{X}_{2}\right)$ was 68.44 with a standard deviation of 10.73. This testing hypotheses with statistical t-test two parties obtained $-t_{\text {table }} \leq$ $t_{\text {count }} \geq+t_{\text {table }}\left(t_{\text {count }}=10.89\right.$ and $\left.t_{\text {table }}=2.00\right)$ with a significant level $\alpha=0.05$, and degrees of freedom 66 . Therefore, $H_{0}$ was rejected, and $H_{I}$ was accepted. This study concluded that advance organizer learning model influenced learning achievements of students at SMA Negeri 3 Sigi on the topic electrolytes and non-electrolyte solutions.
\end{abstract}

Keywords: Advance organizer, learning achievements, electrolytes, non-electrolytes.

\section{Pendahuluan}

Pendidikan merupakan faktor utama dalam pembentukkan pribadi manusia. Pendidikan sangat berperan dalam membentuk baik atau buruknya pribadi manusia menurut ukuran normatif. Menyadari hal tersebut, pemerintah sangat serius menangani bidang pendidikan, sebab dengan sistem pendidikan yang baik diharapkan muncul generasi penerus bangsa yang berkualitas dan mampu menyesuaikan diri untuk hidup bermasyarakat, berbangsa dan bernegara (Djamarah, 2002).

Keberadaan kimia dalam kurikulum SMA, dipandang sebagai ilmu dasar juga dapat dijadikan "kendaraan" untuk mengembangkan/ menumbuhkan kecerdasan siswa, antara lain kemampuan bernalar dan memecahkan permasalahan secara ilmiah. Larutan elektrolit dan non elektrolit merupakan materi pembelajaran kimia yang diberikan di kelas X SMA dan memiliki karakteristik pemahaman dan penerapan konsep. Pemahaman konsep yaitu perbedaan antara larutan elektrolit dan non elektrolit, elektrolit dari senyawa ion dan kovalen polar. Penerapan konsep yaitu saat menguji larutan untuk membedakan sifat-sifat larutan elektrolit kuat dan elektrolit lemah. Karakteristik pokok bahasan larutan elektrolit dan

*Correspondence

Maryam

Program Studi Pendidikan Kimia, Fakultas Keguruan dan Ilmu Pendidikan, Universitas Tadulako

e-mail:maryamkelasb@gmail.com

Published by Universitas Tadulako 2018 non-elektrolit tersebut menjadi salah satu penyebab kesulitan belajar bagi siswa (Nuryani, 2007).

Pokok bahasan larutan elektrolit dan non elektrolit merupakan materi yang sangat menarik dan dekat dengan kehidupan sehari-hari, sehingga proses pembelajaran dapat lebih realistis. Melihat karakteristik dari materi larutan elektrolit dan non elektrolit berupa pemahaman dan penerapan konsep, maka peneliti memilih model pembelajaran advance organizer dalam meningkatkan pemahaman dan hasil belajar siswa. Model ini dikembangkan oleh Ausubel (1960), dimana model belajar bermakna yang bertujuan memperkuat struktrur kongnitif dan menambah daya ingat (retensi) siswa terhadap informasi baru.

Menurut Slameto (2003) advance organizer sebagai materi pengantar berfungsi untuk menjembatani jurang yang terjadi antara apa yang telah diketahui siswa dan apa yang dibutuhkan siswa sebelum siswa berhasil mempelajari tugastugas yang diberikan. Rahayu (2012) menyatakan pembelajaran menggunakan advance organizer dapat membuat belajar bersifat hafalan menjadi bermakna dengan cara menjelaskan hubungan konsep baru dengan konsep relevan yang ada dalam struktur kognitif siswa agar siswa dapat memahami konsep agar efektif dan efisien. Model pembelajaran advance organizer memiliki kelebihan yang digunakan untuk mengatasi kesulitan siswa, yaitu mengarahkan dan menolong siswa dalam pengetahuan baru (Sinulingga \& Munte, 2012).

Dimiyanti \& Mujiono (2006) mengemukakan dominasi guru dalam proses pembelajaran menyebabkan siswa lebih banyak menunggu sajian dari guru daripada mencari dan menemukan 
sendiri pengetahuan, keterampilan serta sikap yang dibutuhkan. Lught \& Snelders (2007) menyatakan guru harus bijaksana dalam mengajar agar dapat menciptakan situasi dan kondisi kelas yang kondusif. Salah satu alternatif model pembelajaran kimia di sekolah yang diduga dapat meningkatkan mutu dan proses hasil belajar siswa adalah model pembelajaran advance organizer.

Tulisan ini dimaksudkan untuk menggambarkan pengaruh model pembelajaran advance organizer terhadap hasil belajar kimia siswa pada pokok bahasan larutan elektrolit dan nonelektrolit kelas X di SMA Negeri 3 Sigi.

\section{Metode}

Penelitian ini dilaksanakan di SMA Negeri 3 Sigi yang terdiri dari tiga tahap yaitu, menjelaskan panduan pembelajaran advance organizer, menjelaskan materi dan tugas-tugas pembelajaran, dan memperkokoh pengorganisasi kognitif. Tahaptahap kegiatan yang dilakukan dalam studi ini mengikuti sintaks model pembelajaran advance organizer yang dikemukakan oleh Aunurrahman (2009).

\section{Populasi dan sampel}

Pelaksanaan penelitian ini pada semester genap tahun ajaran 2015-2016. Populasi dalam penelitian ini adalah seluruh siswa kelas X SMA Negeri 3 Sigi tahun ajaran 2015-2016 berjumlah 148. Sampel diambil melalui teknik purposive sampling. Sampel yang dipilih adalah 34 orang siswa kelas XA yang dikategorikan dalam kelas kontrol dan 34 orang siswa kelas XB yang dikategorikan sebagai kelas eksperimen.

\section{Teknik analisis data}

Data pada penelitian diolah dengan menggunakan metode analisis statistik inferensial (uji normalitas, homogenitas, dan uji-t 2 pihak) untuk menguji hipotesis kemudian menarik kesimpulan tentang perbedaan hasil belajar, dan analisis statistik deskriptif dengan uji $\mathrm{N}$-gain untuk mengetahui sejauh mana model pembelajaran yang diterapkan berpengaruh signifikan terhadap hasil belajar siswa (Sudjana, 2002).

\section{Hasil dan Pembahasan}

Perbandingan tes kemampuan awal dan akbir siswa kelas eksperimen dan kelas kontrol

Tes awal dilakukan dengan tujuan untuk mengetahui kemampuan awal siswa yang berada pada kelas eksperimen dan kelas kontrol sebelum pokok bahasan larutan elektrolit dan nonelektrolit diajarkan kepada siswa. Sedangkan tes akhir siswa dilakukan dengan tujuan untuk mengetahui sejauh mana model pembelajaran yang diterapkan memberikan pengaruh yang signifikan terhadap hasil belajar kimia siswa. Deskripsi hasil pretest dan posttest siswa pada kelas eksperimen dan kelas kontrol dapat dilihat pada Tabel 1.
Tabel 1: Hasil analisis data Pretest dan Posttest hasil belajar siswa

\begin{tabular}{lllll}
\hline \multirow{2}{*}{ Uraian } & \multicolumn{2}{l}{ Tes awal (pretest) } & \multicolumn{2}{l}{ Tes akhir (posttest) } \\
\cline { 2 - 5 } & $\begin{array}{l}\text { Kelas } \\
\text { Eks }\end{array}$ & $\begin{array}{l}\text { Kelas } \\
\text { Kontrol }\end{array}$ & $\begin{array}{l}\text { Kelas } \\
\text { Eks }\end{array}$ & $\begin{array}{l}\text { Kelas } \\
\text { Kontrol }\end{array}$ \\
\hline $\begin{array}{l}\text { Sampel } \\
\text { Nilai }\end{array}$ & 22 & 22 & 22 & 22 \\
$\begin{array}{l}\text { terendah } \\
\text { Nilai }\end{array}$ & 10 & 0 & 64 & 50 \\
$\begin{array}{l}\text { tertinggi } \\
\text { Nilai rata- }\end{array}$ & 40 & 35 & 95 & 91 \\
$\begin{array}{l}\text { rata } \\
\begin{array}{l}\text { Standar } \\
\text { deviasi }\end{array}\end{array}$ & 11,59 & 10,73 & 12,89 & 12,38 \\
\hline
\end{tabular}

Hasil pre test pada Tabel 1 tersebut menunjukkan bahwa perbedaan nilai rata-rata siswa kelas eksperimen dan kelas kontrol tidak terlalu signifikan. Sedangkan hasil post test menunjukkan bahwa nilai rata-rata siswa pada kelas eksperimen lebih tinggi daripada kelas kontrol, sehingga nilai rata-rata siswa yang diberi model pembelajaran advance organizer lebih tinggi daripada nilai rata-rata siswa yang diberi model pembelajaran konvensional. Posttest pada penelitian ini dilakukan pada dua kelas yang dijadikan sebagai sampel yaitu kelas eksperimen dan kelas kontrol dengan jumlah soal yang diujikan sebanyak 22 butir soal yang terlebih dahulu dilakukan validasi soal pada siswa kelas XI SMA Negeri 3 Sigi. Soal tersebut digunakan untuk mengukur kemampuan siswa pada kelas eksperimen dan kelas kontrol (Arikunto, 2006).

\section{Perhitungan N-Gain}

Uji N-gain digunakan untuk mengukur selisih antara nilai pretest dan posttest, sehingga penigkatan hasil tes yang diperoleh pada kelas eksperimen dan kelas kontrol dapat diketahui. Adapun bentuk grafik hubungan nilai pretest dan posttest pada kelas eksperimen dan kelas kontrol dapat dilihat pada Gambar 1.

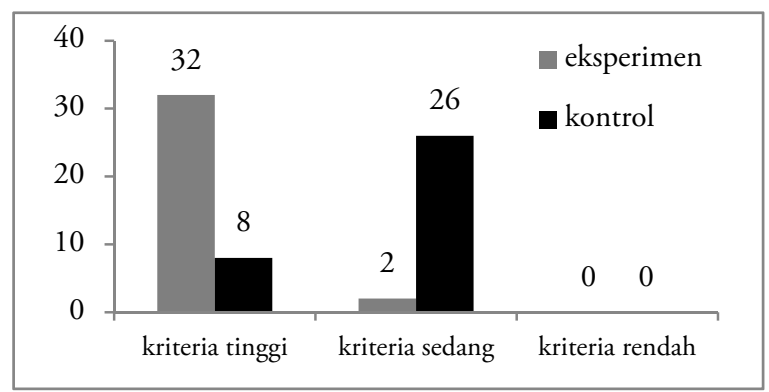

Gambar 1. Nilai N-gain Kelas Kontrol dan Kelas Eksperimen

Berdasarkan Gambar 1 maka perbedaan peningkatan tes hasil belajar siswa kelas eksperimen dan kelas kontrol cukup signifikan. Siswa kelas eksperimen lebih banyak mendapat kategori nilai tertinggi dari pada siswa kelas kontrol, dengan jumlah siswa kelas eksperimen yang mendapatkan 
kategori tertinggi sebanyak 32 orang siswa sedangkan siswa kelas kontrol hanya sebanyak 2 orang siswa yang mendapatkan nilai tertinggi. Hal ini disebabkan pada saat proses pembelajaran berlangsung, siswa yang diajar dengan menggunakan model pembelajaran advance organizer memiliki waktu yang relatif lebih banyak untuk berinteraksi dengan siswa lain berbagi ide dan solusi terhadap masalah yang diberi. Berbeda dengan siswa yang diajar dengan menggunakan model pembelajaran konvensional, siswa hanya monoton ditempat saja tanpa harus berinteraksi dengan siswa lain yang memiliki kemampuan lebih. Model pembelajaran konvensional juga memiliki kelemahan, dimana ketika siswa yang berkemampuan rendah duduk sebangku maka akan menyusahkan siswa tersebut untuk memecahkan dan menemukan solusi dari masalah yang diberi, karena ruang yang diberi untuk berinteraksi dengan siswa lain yang berkemampuan sedang dan lebih sangat sedikit bahkan tidak ada pada saat proses pembelajaran berlangsung.

\section{Pengujian hipotesis}

Pengujian hipotesis pada penelitian ini menggunakan statistik uji-t (t-test) 2 pihak. Kriteria pengujiannya adalah jika $t_{\text {tabel }} \leq t$ hitung $\leq+$ $\mathrm{t}_{\text {tabel }}$ maka $\mathrm{H}_{0}$ diterima dan $\mathrm{Ha}$ ditolak dengan $\mathrm{dk}=$ $\left(\mathrm{n}_{1}+\mathrm{n}_{2}-2\right)$ dan taraf signifikansi $\alpha=0,05$, dimana sampel pada kelas eksperimen sebanyak 34 orang siswa dan kelas kontrol sebanyak 34 orang siswa. Hasil yang diperoleh yaitu taraf signifikansi pada $\alpha=0,05$ dengan $\mathrm{dk}=66$ dari daftar distribusi t student $=2,02$. Kriteria pengujiannya adalah 2,02 $<10,89>2,021$, maka $\mathrm{H}_{0}$ ditolak dan Ha diterima.

Berdasarkan hasil penelitian diperoleh harga $t_{\text {hitung }}=10,89$ dan terlihat sangat jelas nilai tersebut berada pada daerah penolakan $\mathrm{H}_{\mathrm{o}}$ Sehingga dapat ditarik kesimpulan yaitu ada pengaruh signifikan penerapan model pembelajaran advance organizer terhadap hasil belajar kimia siswa pada pokok bahasan larutan elektrolit dan non-elektrolit kelas $\mathrm{X}$ di SMA Negeri 3 Sigi. Adanya pengaruh signifikan tersebut dapat dilihat dari skor rata-rata tes akhir dan standar deviasi siswa kelas eksperimen yang menggunakan model pembelajaran advance organizer lebih tinggi dibandingkan dengan kelas kontrol yang menggunkan model pembelajaran konvensional. Dengan skor rata-rata tes akhir kelas eksperimen sebesar 77,15 serta standar deviasi sebesar 12,89 dan skor rata-rata tes akhir kelas kontrol sebesar 68,44 serta standar deviasi sebesar 12,38 .

Hasil penelitian meta pelajaran Fisika yang dilakukan oleh Dewi (2012) menunjukkan bahwa model pembelajran advance organizer berpengaruh positif terhadap peningkatan aktivitas belajar siswa dan hasil belajar kognitif siswa. Penelitian yang dilakukan oleh Harahap \& Harahap (2012) menyatakan bahwa model pembelajaran advance organizer berbasis peta pikiran lebih baik dalam meningkatkan hasil belajar fisika siswa dari pada model pembelajaran advance organizer tanpa berbasis peta konsep.

Pengujian normalitas dan homogenitas digunakan sebagai prasyarat untuk statistik uji-t, dimana jika data berdistribusi normal dan bersifat homogen maka statistik uji-t dapat dilakukan. Berdasarkan uji normalitas data tes hasil belajar kelas eksperimen diperoleh $x^{2}$ Hitung $<X_{\text {Tabel }}^{2}(6,24$ $<7,81)$ dan normalitas data tes hasil belajar kelas kontrol diperoleh $x^{2}$ Hitung $<x_{\text {Tabel }}(6,24<7,81)$. Melihat hasil yang diperoleh tersebut maka data hasil belajar kelas eksperimen dan kelas kontrol dapat dikatakan berdistribusi normal, sehingga data yang diperoleh mempunyai sebaran hasil belajar yang merata antara hasil belajar rendah, sedang, dan tinggi.

Berdasarkan uji homogenitas data tes hasil belajar siswa diperoleh nilai $\mathrm{F}_{\text {Hitung }} \leq \mathrm{F}_{\text {Tabel }}(1,08$ $\leq 2,38)$, dengan $\alpha=0,05$. Melihat hasil tersebut maka varians-varians kelas eksperimen dan kelas kontrol tidak ada perbedaan dan kemampuan antara kedua kelas yang digunakan sebagai sampel adalah sama dengan demikian sampel yang digunakan pada penelitian ini bersifat homogen.

Wachanga (2013) menyatakan advance organizer dianggap sebagai alat yang dapat memberikan suatu bahan pendahuluan terhadap apa yang dipelajari untuk membantu siswa mengorganisasi, mengingat dan mengaitkan pengetahuan sebelumnya terhadap pengetahuan baru yang dipelajaari. advance organizer dapat meningkatkan motivasi siswa untuk belajar (Shihusa \& Fred, 2009).

Berbeda dengan model pembelajaran konvensional (dengan menggunakan metode ceramah), dalam proses pembelajaran siswa hanya mendengarkan dan mencatat apa yang disampaikan oleh guru. Ketika diberi suatu masalah, hanya masing-masing individu saja yang mencari jawaban dari masalah tersebut tanpa harus berbagi ide dengan individu lain yang memiliki kemampuan lebih ataupun rendah. Sehingga siswa yang berkemampuan rendah ketika diberi suatu masalah yang agak sulit akan terlihat kurang aktif karena tidak tau bahkan timbul rasa malas untuk mengerjakan masalah tersebut, ini mengakibatkan rendahnya hasil belajar siswa pada kelas yang menggunakan model pembelajaran konvensional.

Penerapan model pembelajaran dalam penelitian ini memiliki beberapa kendala pada pelaksanaannya. Kendala yang biasa ditemukan yaitu siswa belum terlalu memahami dan terbiasa untuk belajar dengan menggunakan model pembelajaran advance organizer yang diterapkan peneliti pada proses pembelajaran sehingga siswa agak sulit untuk menyesuaikan diri dan durasi waktu yang digunakan pada proses pembelajaran cukup memakan waktu yang lama sehingga waktu yang telah disusun dalam rencana pelaksanaan pembelajaran biasanya tidak sesuai dengan waktu yang digunakan dalam proses pembelajaran di kelas. 


\section{Kesimpulan}

Terdapat perbedaan hasil belajar siswa kelas eksperimen dan kelas kontrol, sehingga dapat disimpulkan bahwa ada pengaruh penerapan model pembelajaran menggunakan model advance organizer pada materi larutan elektrolit dan nonelektrolit kelas X di SMA Negeri 3 Sigi. Hal ini dapat dilihat dari skor rata-rata post test dari masing-masing kelas, eksperimen adalah 77,15 dan control adalah 68,44 . Hal tersebut diperkuat oleh hasil analisis data statistik dengan nilai $t_{\text {hitung }}>t_{\text {tabel }}$ yaitu $10,89>2,00$ pada taraf signifikan $\alpha=0,05$.

\section{Ucapan Terima Kasih}

Penulis mengucapkan terimakasih kepada Muji'zat kepala sekolah SMA Negeri 3 Sigi, Nellyanti guru kimia di SMA Negeri 3 Sigi dan siswa kelas XA dan XB SMA Negeri 3 Sigi Tahun Ajaran 2015/2016.

\section{Referensi}

Aunurrahman. (2009). Belajar dan pembelajaran. Bandung: Alfabeta.

Ausubel, D. (1960). The use of advance organizers in learning and retention of meaningful material. Journal of Educational Psychology, 15, 262-272.

Dewi, L. (2012). Pengaruh model pembelajaran advance organizer. Jurnal Universitas Yogyakarta, 01(01), 88-92.

Dimiyanti \& Mujiono. (2006). Belajar dan pembelajaran. Jakarta: Rineka Cipta.

Djamarah, S. (2002). Psikologi belajar. Jakarta: Rineka Cipta.

Harahap, R. H. \& Harahap, M. B. (2012). Efek model pembelajaran advance organizer berbasis peta konsep dan aktivitas terhadap hasil belajar fisika siswa. Jurnal Penelitian Inovasi Pembelajaran Fisika, 4(02), 32-37.

Lught, S. F. \& Snelders, D. (2007). Teaching theoritical concepts to large group of design students using fish bowlessin. Journal International Engineering and Product Design Education, 6(12), 10-12.

Nuryani, R. (2007). Keterampilan proses sains. Bandung: Erlangga.

Rahayu, S. (2010). Pengembangan model pembelajaran advance organizer untuk meningkatkan aktivitas belajar siswa pokok bahasan koloid. Journal of Innovative Science Education, 4(4), 497-505.

Shihusa, H. \& Fred, N. K. (2009). Using advance organizer to encanche student motivation in learning biology erurasia. Journal of Mathematics Science and Technology Education, 4(1), 413-420.

Sinulingga, K. \& Munte, D. (2012). Pengaruh model pembelajaran advance organizer berbasis mind map terhadap hasil belajar siswa pada materi pokok besaran dan satuan di kelas X SMA. Jurnal Pendidikan Fisika, 1(2), 1-6.

Slameto. (2003). Belajar dan faktor-faktor yang mempengaruhinya. Jakarta: Rineka Cipta.

Sudjana, N. (2002). Penilaian hasil proses belajar mengajar. Bandung: Remaja Rosdakarya.

Wachanga, S. W. (2013). Effect of advance organizer teaching approach on secondary school students achievement in chemistry in Maara district Kenyaeurasia. Journal of Mathematics Science and Technology Education, 2(6), 122-132. 